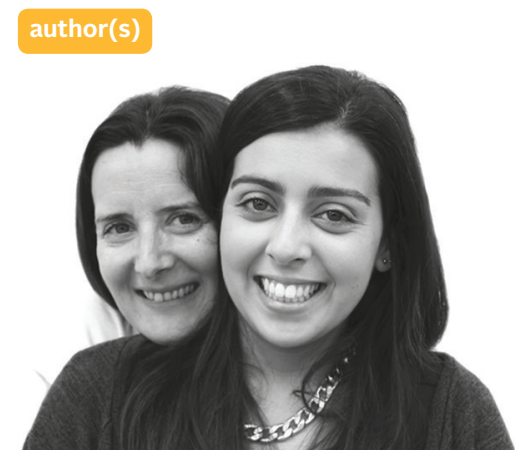

\title{
abstract
}

In Aveiro exists a remarkable awareness about the heritage that falls within the spirit and characteristics of the Art Nouveau style. This is greatly due to the originality and diversity of interpretations that characterize it locally. In parallel, Aveiro also became one of the regions with the most significant collections in the country.

Given their cultural and local importance, we propose to create a route that will improve the work that already exists through the furthering of crossinering of knowledge on this topic and a cataloging, crossing and grouping of all the information about the artefacts which are scattered by these cities in order to make it easier to search and access their information. The research is at its beginning, and in a first phase it will be focused on the contents assigned to each of the artefacts. These will be methodically studied through an authorial interpretation (aesthetics) which will then reflect the evolution of the buildings (technology) and Subsequently the story (program) to the national heritage.

Filipa Vieira filipa.vieira@ua.pt Helena Barbosa helenab@ua.pt Universidade de Aveiro

for a mobile app, which is in its initial stage of development. Briefly, this poster presents a brief history of the manifestations of Art Nouveau in Aveiro and lilhavo and proposes a new roadmap for these cities.

This research will contribute to an understanding of the evolution of the building from its construction to the present day its level of structural recovery or lack of it and also its rehabilitation It will also contribute to knowledge about the buildings that mantaned (or not) their unique sesig (o Nowe tage in this region is based on the personal the that owners attributed to their artefacts, as well as the training and the artistic ability of its authors strongly influenced by personal temperament and technique that deserve to be studied.
New Routes for Art Nouveau in Aveiro and Ílhavo

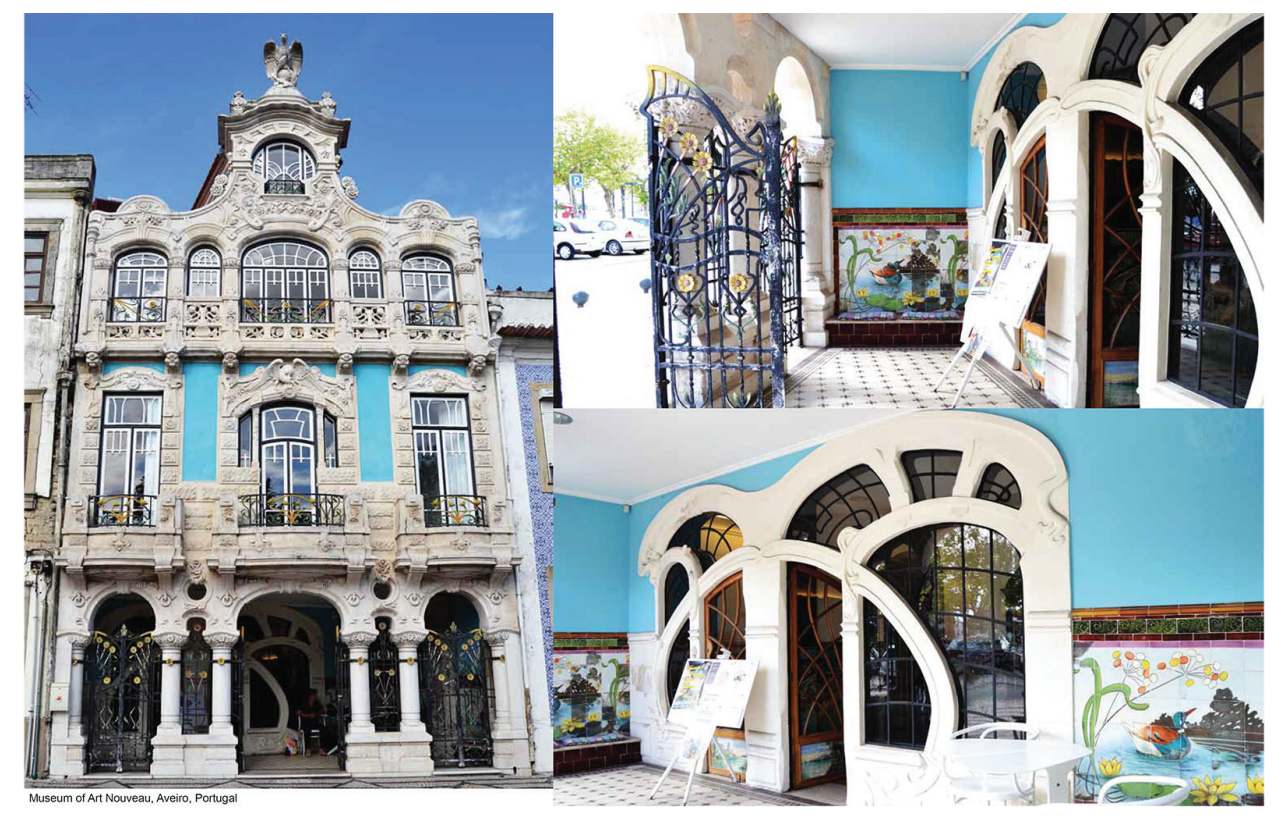


Between 1890 e 1914 Art Nouveau appeared in Portugal, with basic characteristics that exhibit a degree of uniformity with "close visual parameters" as a "result of individual interpretations, which adap to the "materials of each region and to the taste"

of its interpreters (Neves 1997: 16). "Characterized by a profound individualism", strongly influenced by the personal technique and sensitivity of its authors, it resulted in the creation of a unique and individual artefact (1997: 16). Although the architect Francisco da Silva Rocha (1864-1957) had some previous influences of the Art Nouveau style, the archetypal of what's recognized as Art Nouveau in Aveiro occurs in 1905 .

The cultural context and political circumstances in Portugal were far from the European reality and had some influence in the style differences of the Art Nouveau style in Aveiro and Ílhavo. In these areas, the development of the ceramic and maritime industries combined with the appearance of the railway, created the necessary accessibility conditions for the appearance of the first manifestations of this artistic style in re In the middle of the first decade of the twentieth century, references to style were increasingly frequent, emphasizing its tasteful design and quality of execution, tracing a difference in economical and social status in the city environment.

In spite of this style developed in the urban centre of Aveiro, there are also some farther centres amongs which highlights illhavo. Different examples of it can be found in both cities although not extremely rich in ornament, by their architectural value bring fresh proposals of social life, winning a significant role in local tile. The Fonte Nova factory is an example of that being one of the major contributors to the spread of Art Nouveau tile in the style of the region which gave the buildings an aesthetic refinement, mostly on the frieze of the façade level, that the architecture alone could not ever do
In turn, illhavo has always identified itself with the development of the district capital (Aveiro) trying to keep up in order to become a city with an assorted estate of interpretations of the style. Innovation and a desire to distinguish was boosted by seafarers of ílhavo, travellers par excellence that would bring from diverse European countries and from the colonies in Africa, different ideologies to use in the design of its artefacts, that are responsible for shaping its authorship.

The rising local middle class that resulted of the proliferation of industry and trade mainly requested the construction of these buildings, and so was not at all a style exclusive to an economical or differentiated cultural sector. The region Art Nouveau was merely decorative, a different way of living, which proclaimed itself as cultural status.

The ornament represented much more than a simple decoration, it was the expression of a whole, which reflected an ideology of life, and a cultural and mental elevation. In Aveiro there is thus two different expressions concerning the general level of understanding and ornamentation by the artists, by one hand the "grace, fragility, sweetness", by the other the "virility (...) the soundness and a certain austerity" (Neves 1997: 19).

We presume that the artefacts that have a less ostentatious ornamentation within the façade have possibly been conditioned by economic reasons of a less wealthy middle class compared with the more sumptuous artefacts, both inside and outside of the buildings, reflecting a higher monetary power.

\section{Art Nouveau new routes in Aveiro and ílhavo}

In the region of Aveiro, Art Nouveau developed in the coastal cities of the estuary, especially in the district capital, in areas near to tile factories and within areas with considerable population density. In Aveiro, there already exists a route by which you can visit some of the style examples, but it doesn't make a reliable survey of existing assets, meaning a lack of information and cataloging about the Art Nouvea heritage. Despite all the improvements that have been made in the Art Nouveau Museum of Aveiro and its city route such as reference signs to the

rtefacts or the creation of an almanac that has their location and a brief description, there is no available information in other cities.

The dispersion and lack of information related to this style creates the necessity of creating a new route that will make possible the integration and organization of new elements in an Art Nouveau heritage catalogue. For this, its features will address their themes, materials, colours, tile, authorship and its history.

The feasibility of this route will consist of a mobile app', which will allow a more accurate way to understand the specifics of the design and author interpretations that result in the uniqueness of the artefacts in this region. This will be a device that can recognise and read reference signs as "qr codes". So, the access to previously selected information about each artefact will be easier. Therefore, this mobile app will provide new experiences to the tour based on those characteristics. This way, we want the user to time travel between nowadays and the construction date of the artefact through photographic records showing the artefacts over time and contents about its history. Considering that the project is in an early stage, more specific examples of the mobile app cannot be given - its creation is predicted, but its implementation has not yet been fulfilled.

\section{Conclusion}

It is concluded that the Art Nouveau in this region became unique due to an important diversity of differentiating itself according to the training of its interpreters, which would also be suitable to the lifestyle and cultural demands of those who commissioned it. The mobile app will serve as the mean of excellence for the integration of content that can go further than the display of the artefacts. This way, it will be made an increased contribution and a offer of access to knowledge about the history of Art Nouveau in Portugal. ootnotes

hard copy available

References

Denis, Rafael Cardoso (2000) Uma Introdução à história do Design, São Paulo: Edgard Blucher Ltda.

Greenhalgh, Paul (2000) Art Nouveau 1890-1914, London: V\&A Publications.

Neves, Amaro (1999) A "Arte Nova" em Aveiro e seu distrito, Aveiro: Câmara Municipal de Aveiro.

Neves, Amaro (1997) Da arte nova em Aveiro: o porquê da diversidade do estilo, Aveiro: Câmara Municipal de Aveiro. Rodrigues, Manuel Pereira (1996) Os industriais da cerâmica: Aveiro, 1882-1923, Análise Social, vol. XXXI, no. 20, 30, pp. 631-682.

Rogers, Y., Sharp, H. and Preece, J. (2011) Interaction Design: Beyond Human-Computer interaction, USA: Wiley.

Tidwell Jenifer (2011) Designing Interfaces, Cambridge: O'Re Media.

\section{Aknowledgements}

This work is funded by national funds through the Foundation for Science and Technology - FCT - in the scope of project PEst-OE/EAT/UI4057/2014 